\title{
Being a mobile international postgraduate research student with family in the United Kingdom: conflict, contestation, and contradictions
}

\begin{abstract}
The internationalisation of higher education has influenced the dramatic rise in the mobility of students, academics and knowledge across borders. There has been growing research interest focusing on international students studying abroad. While the student experience is an area of education that is often-researched, most research focuses on experiences of undergraduate students. Also in the context of international students, greater research emphasis has been placed on the academic experiences and support available for undergraduates. While such research is important, less attention has been paid to the non-academic experiences of International Post-Graduate Research Students with Families (IPGRSF). This paper seeks to fill this gap by focusing on the social worlds of IPGRSF in the United Kingdom (UK), examining students' nuclear family contexts which are often marginalized in discourse. The paper legitimises the IPGRSF such subaltern world by focusing on how students negotiate the demands of this subaltern world; how they negotiate their roles as research students with their other roles as spouses, parents and the interrelation of these roles and how the university as an institution interacts with the students' subaltern world. The findings show that language plays a significant role in shaping the process of mobility as well as influencing the students' and their families' integration and networking in the host country. Also, the findings suggest that students often had positive experiences at departmental level, but felt let down by the wider university support.
\end{abstract}

Key words: Mobility, international students, family

\section{Introduction}

The internationalisation of higher education (HE) has resulted in a dramatic rise in the mobility of students across borders (Verbik and Lasanowski 2007; Singh et al. 2014; Kritz 2015). The number of globally mobile students has increased from 2.1 million students in 2002 to 3.7 million in 2011 (The Organisation for Economic Co-operation and Development 2011, Choudaha and Chang 2012). Every year, a large number of international students travel to the United Kingdom (UK) to pursue higher education. In 2012/13, about $18 \%$ of the UK higher education student population was international students (HESA 2014). In postgraduate level, this percentage has risen to $37 \%$ in 2013 (HESA 2014). This meant that more than 1 in 3 the UK postgraduate students are international. Such growth in the number of international students contributes greatly to the UK economy (BBC News 2012). 
The term 'internationalisation of higher education' is a complex and contested concept. For some, internationalisation of higher education is related to the provision of education in relation to the networks of universities spread across the globe. For others, it refers to the internationalisation of knowledge, in that knowledge production is harmonised through the creation of unified global research communities (Knight 1993; Qiang 2003; Luxon and Peelo 2009).

This paper refers to internationalisation of HE as one way in which educational institutions respond to the impact of globalisation. This includes ways in which they respond to the individuality and cultural identities of migrant students in their organisation and provision of HE in terms of teaching, learning and other support services (Knight 1993; Qiang 2003). This definition, suggests that internationalisation is an active and interlinked process that includes integration and contributes to the financial sustainability of the international dimension of the institution.

Responding to the needs of increasing numbers of international students, UK HE policies have become increasingly internationalised (Stier 2002; King and Ruiz-Gelices 2003; Bartram 2008 Altbach 2015). This internationalisation can be categorised into 'symbolic' and 'transformative' (Turner and Robson 2008). As symbolic, universities are represented as active players in the global market with the primary concern of generating revenue from international students (Schweisfurth and Gu 2009). Thus international students are viewed as clients that have to be offered a range of support services to meet their academic needs (Bartram and Terano 2011). The transformative internationalisation of education perceives Universities' as primarily concerned with knowledge sharing, cooperation and integration of the international dimension into the teaching, research and support services (Schweisfurth and Gu 2009:464).

Internationalisation of HE has resulted in an increased research focus on international students' motivation for mobility (Heczková and Jašková 2010), interculturality (Schweisfurth and Gu 2009; Denman and Hilal 2011), language (Toohey and Norton 2000), integration and networking (Bennett 2006, 2009). Although these various studies discuss aspects of international student education, they do not seem to fully address the complexity of needs and experiences of international postgraduate students with families (IPGRSF). Most of the discussion seems to assume a degree of homogeneity among students, with the major focus being on undergraduate bachelor student experiences. This has left unexplored the unseen family world of IPGRSF, thereby raising questions about the significance that this unseen world may have for the students' educational experiences. This paper redresses this gap by considering the experience of this particular group of international students viewed from a symbolic internationalisation perspective.

Drawing on the notion of symbolic internationalisation of HE, the current study attempted to bridge this gap and shed further light on the complexity of the needs of international students by analysing the perspectives of IPGRSF. This notion is used as it gives a voice, not only to these students, but their families as well. Using a qualitative case study approach and basing the findings on interviews with five families, this study highlights different though interrelated aspects of IPGRSF in relation to their mobility for education, including their attempts to integrate and university support. 


\section{International students' experiences}

The review of literature highlights multiple dimensions influencing international students' experiences. Adopting the symbolic approach to understanding internationalization of HE, this paper focuses on how language and institutional support influence the educational experiences of IPGRSF. Obviously there are many factors that affect IPGRSF including among others the gendered nature of mobility, value conflicts, social networking, provision of childcare or schooling and funding opportunities to name but a few. Due to limited space this paper focuses on language and institutional support. In addition to the other issues mentioned earlier, these two issues are useful indicators of the extent to which universities posits and handles the needs of IPGRSF as clients rather students in a classic sense.

\subsection{Language}

The English language can be seen as a language of elitism, power and prosperity, thus playing a vital role in influencing decisions about study migration destinations. Denman and Hilal (2011), for instance, argue that the English language has significant impact on Arab student educational migrations. They argue that most Arab students prefer to migrate to countries such as the UK, United Sates of America (USA), and Australia where education is obtained through the medium of English. Bartram and Terano (2011:30) support this view by arguing that international students migrate to the UK and the U.S., 'where the perceived currency of improved English language competence as a result of residence and study acts as a major draw'. In addition, Altbach (2015) suggests that one the reason for students choosing the English speaking country as destination for study is that because some scholarship providers encourages students to study in countries like the UK, the US Australia where it is believe that HE education in these countries has outstanding reputation. Researchers ( Ibrahim 1999; Toohey and Norton 2000; King and Ruiz-Gelices 2003; and Gallucci 2011) consider English language as one of the very important factors that can influence students' experience. Regarding language, this paper focuses on how competency in English language influences the experiences of IPGRSF.

Language can act simultaneously as a vehicle of both empowerment and disempowerment. The level of competency in the English language prior to migration impacts on how students communicate with native English speakers and integrate in the host community (Toohey and Norton 2000). This suggests that lack of English language competency can negatively impact on students' ability to negotiate their way through a new country's cultural codes and access services. Failure to master the language results in isolation, which in turn increases homesickness which subsequently affect the educational experience (Toohey and Norton 2000). Inability to adequately use the host country's language can be dis-empowering in that people feel as though they have become insignificant entities.

Language is likewise closely linked to issues of identity and citizenship. Ibrahim (1999) and Gallucci (2011) suggest that lack of ability to speak the host country language (both in terms of 
accent and cultural understanding) contribute to the development of the concept of the 'other'; instead of integrating, the students starts to regard the people of the host countries as the others. This is thus likely to be a problem for most IPGRSF as some of their family members might not have adequate language skills to socialize and access services. This can be a problem, as well, for the students themselves. Maclean (2010) highlighted challenges that that international students may face related to lack of proficiency in English language, such as its negative impact on academic performance and confidence.

The literature on language and student mobility also suggests that students migrate to countries where they expect to find people who speak their native language and understand their culture (Skeldon 1997, Bennett 2006, 2009). These people were found in religious and national groups that are organized by students or those they identify with in the host country (CSSA 2009; USISOC 2012; SSCL 2012) and with whom they may share languages with. This illustrates the significance of language in the mobility decisions. Although such people might be considered to provide a reliable source of information in the decision-making process and assistance and support in the host countries, sometime their usefulness to the migrant student's academic development can be contested. Schweisfurth and $\mathrm{Gu}$ (2009) argue that the congregation of international students with those with whom they share languages limits their opportunities to interact with the multicultural environment inside and outside the university.

\subsection{Institutional support}

Institutional support in relation to the experience of international students is driven by the concept of consumerism where many educational institutions perceive international students as consumers who are buying the educational service provided by the institution. This is reflected in the high fees paid by international students in comparison to local students. Bartram (2009), Tian and Lowe (2009) explain that, because of the high fees that international students pay, they are often viewed by UK and U.S. universities as clients who pay for, and should therefore be provided with services and support. These include services to address different aspects of integration, including academic support as well as campus facilities e.g. accommodation, banking and healthcare. In addition provision of well-structured and accessible material and moral support for students play an important role in enhancing students' educational experience.

However, this analysis of needs is often biased towards single and younger students without family and childcare responsibilities. The way these services are provided demonstrates the tendency by universities to view international students as a homogenous group with similar needs. This demonstrates how educational institutions may fail to address the needs of IPGRSF. Consequently, the needs of IPGRSF are often misrecognized as different from those of younger single students or even as absent. Consequently, PGRSF may not effectively engage in their academic work.

Although there might exist some slight similarities between the needs of the domestic mature students with family and international postgraduate research students, in regards to the demands of 
family responsibilities for instance, the needs of IPGRSF are different, specifically in relation to the fact that IPGRSF migrate to a different cultural context and thus have a lot of adjusting to do compared to their counterparts. Therefore, experiences and needs of IPGRSF should be researched in their own right. Adopting symbolic internationalisation to understanding the experience of IPGRSF, this paper focuses specifically on the experiences of these students in relation to language and institutional support. Within this framework, this paper explores how language and institutional support impact the experiences of IPGRSF.

\section{Methodology}

To explore the issues highlighted above, we adopted a qualitative case study approach to understand the experiences of IPGRSF from their own perspectives. The approach was appropriate because of its usefulness in providing a contextual understanding of people's experiences (Mwale 2014); and also illuminates the 'contextualised exploration of conflicts' ... and... 'contradictions' (Mwale 2014; 139) of the participants' experiences. The participants in this study were IPGRSF at a UK institution and were selected purposively with specific criteria of (a) being registered fulltime students at the time of the interview; (b) had completed at least six months of study; (c) had at least a child. The purpose of the approach used in this paper is not to generalise findings but provide a contextual understanding of people's lived experiences (Mwale 2014). For purposes of confidentiality, the names of the participants, university where they were studying were omitted or replaced with a pseudonym in this paper. The participants are referred to as a family followed by a number and a description as to whether they were the student or not. The countries of origin of the participants are not mentioned but reference is made to the regions they are from.

We selected seven individuals who represent five families. Where possible, we interviewed both adult units of the family (i.e., husband and wife). This was not possible in all cases due to cultural barriers or to partners not being present in the UK at the time of the interview. In such cases, we used the voice of one unit of the family as reflective of the entire family. We categorised the five families into the following four types:

Type 1: Husband and wife both live in university accommodations in the UK. We interviewed separately both the husbands and the wives in two families of this type.

The student in Family 1 is a qualified psychologist from Far East-Asia. She worked as a university lecturer and was about to complete her PhD in Psychology at the time of interview. She had been living in the university's family accommodations with her husband and two children, but had needed, due to health reasons, to send her elder daughter (aged two) home to live with grandparents. The student's husband, who is also from Far East-Asia, is a qualified primary school teacher.

The student in Family 2 is a qualified psychologist from South-East Latin America. She was in her first year of a PhD program in Psychology She was living in the university's family accommodations 
with her husband and a son. Her husband is also a qualified psychologist from South-East Latin America.

Type 2: Husband and wife both live in an off-campus rented property in the UK. We interviewed one family of this category, referred to as Family 3. The student is a qualified educationalist from the Arabian Gulf. He was in the third year of a PhD in Education at the time of interview. He was living in the UK with his wife and two children. For the family cultural sensitively, we were able to interview only the husband from this family.

Type 3: The husband is studying in the UK; his wife and children had accompanied him for a period of time, and then returned home. We interviewed one such family, referred to as Family 4. In this case we interviewed only the husband, as the wife was no longer in the UK at the time of interview. The husband is a project manager for educational projects and enterprises from West Africa. He was in his third year of a PhD in Education at the time of interview.

Type 4: The wife is studying in the UK, whereas the husband is working in a different country. We interviewed one such family, referred to as Family 5. In this case, we interviewed the wife, who was living with her daughter in university accommodations. The student was in her first year of a $\mathrm{PhD}$ programme in Education at the time of interview. In West Africa, she had worked as a teacher. She had previously lived in Europe, the UK and North America.

Data were collected and recorded from the five families using semi-structured interviews. In using this approach we were able to understand the contradictions and contestations of their experiences. Two sets of interview schedules were used: one set with questions for students that included questions on their education experiences at the institution and another for their spouses mostly omitting question on education but their social interaction and experiences in the new environment. Each of our participants was interviewed separately. The data were analysed thematically using a six stage analysis suggested by Braun and Clarke (2006). This includes themeizing the data; transcribing the interview verbatim and interpreting the data in relation to the emergent themes.

The methodological issues that arose in the process included issues of relating to generalizability of the study findings; while the findings are not intended to be generalizable the issues raised by the participants in this study provide good insights to consider for provision of education to IPGRSF. In addition, there was also need to consider our own prejudices as researchers who may have shared some of the experiences of the participants. For instance two of the researchers were themselves IPGRSF at the time of the study. There was thus need to consider how our own experiences shaped the interview and even interaction with the participants. This is not in any way to bring into doubt the integrity of the paper rather to demonstrate an awareness of the fact that the accounts presented may have different interpretations depending on how they are read. 


\section{Findings}

\subsection{Language Impacts on the Experiences of IPGRSF}

The interviews with participants show that language as an influential factor to the experiences of IPGRSF in the UK. In this paper language is understood as a linguistic code that people use to communicate verbally or in written form; and also as a reflection of culture, in that people use language to convey values and obtain understanding from others about their cultures and ways of doing things. Language was indicated as a key factor in helping the IPGRSF to integrate in the host countries. 'Integration' here refers to the ways in which IPGRSF built relationships, as part of the process of becoming established, thereby enabling the students to participate in cultural ways of life during the process of settling their families in these communities. This does not necessarily mean adoption of the local cultural norms of the host country.

Although initially the participants expressed that mobility for studying was an exciting process, they tended not to have thought about the importance of the family as a whole, and not only the student, having competence in the host country's language. Thus, on arrival, some found that lack of proficiency in the English language was a limiting factor as it restricted their socialisation with locals. This was frustrating for most of them and resulted in feelings of isolation and alienation.

Actually I found it scary when I came here, because... my English was very weak... So, on arrival I found it a bit scary because I always ... I [thought] I would cope with the new culture, with the new language, the new people...but the reality was different....

.... I always stayed at home, I became less confident to face people, so every day after Fajer [morning] prayer I spent one hour to learn English with a website [BBC website] it's a free website just for one hour

(Non-studying partner of Family 1)

Although we have passed the required language test (IELTS), we still feel that we have some difficulties in dealing with the English language in real day to day communication.... Although we are good when we use English for academic purposes we still struggle with communicating with people in the street.

(Student partner of Family 3)

The above quotes demonstrate the significance of language in the mobility process as a carrier of communication and culture, with the inability to express oneself resulting in feelings of isolation. Though this affected students as well, language difficulty was particularly problematic for the family members who were accompanying the student; who were often not included in the social/academic interactions in which the student participated. Such interactions play a key role in building relationships and networks, understanding the host country's culture, and improving language skills. For the non-studying family members, building networks was closely linked with having a social life for themselves. Lack of proficiency in the language was often explicitly expressed as a source 
of frustration by male partners accompanying their wives to study. For most of the male participants who saw their role as being guardians of their families they found that their inability to articulate themselves as disempowering. In this context therefore, language was not merely a tool of communication but equally a contestation that had potential to empower or disempower the students and their families in their new settings, as illustrated in the quote below:

I felt isolated, very isolated because I couldn't speak [...] speaking was very important for me....I can't understand what they are saying as I am not from here... It was like I didn't have a mouth. It felt like I was one without mouth.... [I was] scared you know.

(Non-studying partner of Family 2)

This quote describes how language acted as a tool for disempowerment in that it restricted the individual's ability to interact with the community. In addition to the language barrier, the participant also refers to a cultural understanding of the host country's community. The quote suggests that failing to integrate in the host country's communities was not only a result of language as a purely linguistic code, but also as a cultural understanding. Thus failure to understand the destination country's language (i.e. English) and culture made our participants feel vulnerable, isolated and disempowered. For the students, having a family that was at unease in the new environment with all the adjusting that was required of them including academic adjustment as well, meant that students found themselves with even more challenging responsibilities than they had anticipated. It made them work at improving their own language proficiency and adapting to the demands of studying at HE and also work harder to helping their family members, mostly their partners, to settle down. Settled and happy spouses as will be shown later were seen as crucial to the students positive experience at postgraduate level, arguably at all levels of study as well.

The data suggest that some of the non-studying partners, took active steps to improve their language skills by buying English lesson CD's and accessing websites for self-taught language lessons. This is interesting, as it raises the potential for an important service that a university could provide (and here did not) to support students' families. The question remains to extend these resources that were meant to help improve the individuals' language proficiency contributed to improving their understanding of the culture associated with the language itself.

We note that among the stated motivations for migration of students and their families was the desire to improve language skills and to learn about other cultures, which influenced the choice of the destination country. However, the reality of living in the host country was such that it presented an unexpected contestation as learning the English language became a challenge in its own right, which required a rethink or drove them to a different coping mechanism. As stated earlier, lack of English language skills resulted in isolation as the participants found it very hard to mingle with the local communities. In order to deal with this isolation and alienation, our participants found themselves associating with families and groups who spoke or shared aspects of their native language and understood or shared their culture as illustrated in the quotes below: 
When you look for others you look for those who are more similar to you, who speak your language, because then you know the rules, you know... when you going to socialise... you not gonna step on anybody's toes.

(Student of Family 2)

I always go to [name of a mosque] or [another name of a mosque] ...because I found the right group of people that speak my language, that live in these mosques [accommodation attached to these mosques], we always arrange BBQ, football match and so on...

(Non-studying partner of Family 1)

We identified two strong motivations for the desire to associate with people from the students' and families' familiar cultures. Firstly, it can be argued that lack of language proficiency leaves students feeling isolated; therefore communication with people who speak their language facilitates their settling in. Secondly, the migration process itself was, in part, supported by these networks of people acting from the host country and, upon arrival in the host country, these individuals continue to act as hosts and guides in helping students to settle in.

While these forms of association help students establish networks and support for their families, these relationships do not necessarily promote their academic achievements or contribute to improving their language skills. - Instead, it makes them remain with what they know and consequently may not achieve what they came for. When they associate primarily with people from their home country culture, students and their families reduce their exposure to people who might support them in learning the local cultures, way of life, and knowledge of how to access services and much more improve their language which was one of their desire. Despite the disadvantages, students and their families clearly feel a strong attraction to these groups. At issue here is that while the IPGRSF express a desire to improve their language skills and their understanding of the cultures of the host country, they simultaneously do not want their families to feel isolated from 'home' and 'culture'. It is in these situations that contradictions and contestations were made explicit by our participant's accounts. On one hand their goal was to learn a new language and experience new cultures, on the other hand the attraction to familiar languages and groups they shared their cultural backgrounds with that provided a social interaction for their families seemed to be an easy option.

This language dilemma illustrates the contradiction between what students and their families thought they wanted to achieve and what the reality in the host country presented them with. It demonstrates the way in which students and their families tend to emphasise their established cultural norms and beliefs, thus minimising the space in which to challenge their home country's culture. This is not to delegitimise non-British cultures or the significance of the relationships with people they identify with, but it is a demonstration of the challenge of emphasis placed on learning cultures in marketing discourse of international education of students studying abroad that does not seem to consider the possible challenges that students may encounter. It also raises questions about how associating with people they shared cultural and language backgrounds with may impede learning new language and experiencing new cultures -a goal they migrated for. 
The discussion above highlights the complexity of the experiences of the IPGRSF in relation to language, which is different to domestic research students who may not have to learn a whole new language or cultural way of life. Also, it illustrates contradiction and contestations between conflicting family and academic needs. Language was obviously an issue for our participants; it presented some contestations as it made them feel disempowered, incapable of articulating themselves and thus limited their ability to socialise with English language speakers in the host country. The contradictions were thus explicit with regards to the choices that the students made when responding to the challenges of language by building social networks with individuals or groups with whom they identified with. Yet in doing so, they were aware this could limit the space for learning new cultures while challenging their own cultural upbringing and language which was their primary goal for migrating. The contestations that a new language presented therefore had implications for the students experiences as difficulties that family members encountered had to be dealt with by the students who in most of these cases were seen as scholarship holders and the university's primary responsibility.

\subsection{The impact of institutional support on IPGRSF experiences}

The data suggest that our participants distinguished between two forms of institutional support. The first form addressed their direct academic needs via help and support that they received from their schools/departments, delivered particularly through their supervisors. The other form addressed their practical needs and those of their families (e.g. accommodation, children's playgrounds, and healthcare). The data show that our participants did not perceive the support from their supervisors with their non-academic needs as part of the broader category of 'institutional support', while they defined the services addressing practical issues as institutional support that the university was obligated to provide. The participants seem to appreciate the most the support with non-academic issues that supervisors provided; they refused to recognise it as institutional support. They believe that their supervisors went beyond their institutional duties to assist them in many aspects including supporting them to resolve issues in their social lives.

'When I came from [Latin America] I was not sure about settling down in England. My supervisor was good he introduced me to [a Latin American] family. They were helpful it made me feel at home. He was also good at the fact that I had a family, he would reschedule meetings at short notice and meet me at times that were convenient for me. I think he is the only person who understands my family situation'

(Student partner of Family 2)

'My supervisor was the only person who really understood my situation. I was in tears over my daughter being away from me back home and he gave me time to go and visit her...without my supervisor this would not have happened. He also helped me find accommodation when I had to move house and he advised me about good schools for my daughter...'

(Student of Family 5) 
The students perceived their supervisors as the human face of the university, as they provided the primary personal contact during students' everyday academic lives. They felt that supervisors understood them personally and academically, and hence appreciated their challenges more than the university as an institution.

On a social and academic level, supervisors were thought to understand the challenges of being an IPGRSF; thus demonstrated more flexibility than others in arranging meetings and tutorials. This included allowing sufficient time for meetings and encouraging the students to address their issues and discuss their work without feeling rushed or pressured. The main point to be drawn here is that it is unsurprising that the support that the students received from the supervisors was not extended directly to the family by the university. This is what is generally expected and most the universities see the role of supervisors to be only on academic aspects of the student life. However, here what the problem seem to be IPGRSF as they tend to require support beyond the academic part. They seem to require a personal and human support that some supervisors extend to the students; and this human face that these supervisors add to the institution that was useful in helping the students to support their families. However, the students expressed dissatisfaction with the logistic and nonacademic support provided by the university as an institution. Most of the participants felt that existing support services including the inductions provided by the university are more focused on the needs of single, young students and do not consider the complexity of IPGRSF needs as reflected in the quotes below:

'...the housing office is not very supportive, we haven't had that good experience. To get anything from them you have to bother them all the times which oddly enough seemed to annoy them. I complained about rubbish and noise from the neighbouring building because my children couldn't sleep because of the noise so I couldn't study as a result. They dismissed my complaints as just being too strict or something...'

(Student of Family 2)

[...] I don't think this university supports students with family at all, most of the students who live on campus are international students and because of our lack of understanding our rights we don't get what we need, so it seems we have to demand things if we are going to have anything, but we can't complain cause we don't understand the rules. ... I don't think they support family here, they think all students are single and have not responsibilities at all...'

(Student of Family 3)

Of note here is that, when our participants talked about the university, they differentiated between the supervision and other support they obtained from their schools and departments and the support obtained from other university service offices rather than seeing departmental support as part of a unified institutional whole. The support provided by the supervisors was not regarded as 'university support' but as something distinct and personal. This could have two possible explanations: firstly, it could be that because of the nature of the relationships they had with their supervisors, they 
considered this support to be separate from the less personal institutional university support mechanisms. This could be due to the nature of the $\mathrm{PhD}$ provision in the $\mathrm{UK}$ where supervision is commonly provided by main and second supervisors, rather than teams of more than two supervisors. The consequent personal nature of the relationship between the student and the supervisor results in students viewing their supervisors with a Durkheimian lens (Davies 1994), given which the supervisor is not seen as embedded in the wider institutional support structure but rather as a separate entity. Secondly, it could be that because of their family situations, they felt that any institutional support should be organised as a whole providing seamless service that takes into account the wider socio-personal issues that affect them.

It was in this logistical aspect of institutional support that most of the participants felt let down by the university. Although the university has a structure in place via which it caters to international students in general, it lacks provisions for IPGRSF. Many services that the university offers do not seem to consider the needs of IPGRSF, such as for accommodation waste collection, noise control and playgrounds/space for children. Left unaddressed by university services, these issues add to the practical worries with which the IPGRSF need to cope, in addition to their family and academic responsibilities. While it can be argued that local students would face the same practical and logistical challenges, it should be noted that the challenge for local research students with family is different as they are likely to be well informed about the system in the country compared to IPGRSF. These reported student experiences are consistent with our view that the university conception of students is that of young, single undergraduate students. Given this view of students, universities neglect the needs and experiences of IPGRSF. This joins additional challenges to the many with which the IPGRSF already contend.

\section{Conclusion}

The paper has argued that educational mobility has a significant impact on the IPGRSF. It has shown that language plays a significant role in shaping the process of mobility as well as influencing the students' and their families' integration and networking in the host country. Language was a conflict encountered not only by the students, but by their family members who were often excluded from social networking because the university focus and support is aimed at the student and not their families. These interactions were often crucial in developing the language skills which ultimately helped in networking and integration. Therefore, language became a tool of communication that on one hand empowered the students while on the other disempowered their families because of their lack of proficiency in English. Thus, most of the family members felt vulnerable, isolated and disempowered. This had an impact on students' experiences learning experiences as they found themselves having to support their families to settle down much more than they had anticipated. In addition, language was equally an issue for some of the students, while most of them thought they understood and were proficient in English language prior to mobility, on arrival in the host country they felt that their language skills were not as good. The lack of proficiency in the language for both IPGRSF and their families resulted in a tendency to socialize and network with people who spoke their home languages and may share similar cultures. In doing so, they probably miss the 
opportunity of improving their English language, learn about the culture and if they integrated with the host society. Their response to the challenges of language they face in the host country exposes conflicts and contestations. While one of their motivations for migration was to learn new cultures and learn other languages, their tendency to congregate with people who spoke their language and understood their cultures partially frustrated the achievement of this goal.

This constellation of circumstances places significant pressure on IPGRSF emanating from family and academic responsibilities. The students have demonstrated ways in which they manage these responsibilities. Also, they highlight how the support provided by the university helps or fails them in their pursuit of academic success. The data showed that students often had positive experiences with their supervisors and staff at departmental level, but felt let down by the provision and organisation of wider university support. There is a sense that the university support is geared towards single young students and lacks understanding of the complex needs and challenges faced by the IPGRSF.

The way these factors interplay shapes the experiences of IPGRSF in the host country. The existing logistic and non-academic support that the university provides for the IPGRSF appears to be insufficient. Students and their families found themselves negotiating a number of contested and contradictory issues with which they had anticipated support from universities in the host country, in order to cope with their domestic, social and academic needs. There is need for further research in this area. This study paves the way for other researchers to explore this area further by exploring the contestations faced by IPGRSF in their pursuit of education in the UK.

The research discussed in this paper suggests that that in order to enhance the support for IPGRSF, there is a need to challenge the normative assumptions about the profile of international students. There should be a deliberate effort to deconstruct the notion of international postgraduate students which currently seems to conflate IPGRSF with the local or home young students and as having similar needs and concerns. Doing so would help bring about recognition of the diverse nature of the student population and a platform for provision of equally diverse services and solutions. Better support services for IPGRSF would recognise that they have families and would provide services to support them as families rather than only as individual students.

\section{References}

Altbach, P. (2015) Perspectives on Internationalizing Higher Education. International Higher Education, 27, pp. 6-8.

Bartram, B. (2008) Supporting international students in higher education: constructions, cultures and clashes. Teaching in Higher Education, 13(6), pp. 657-668. 
Bartram, B. and Terano, M. (2011) Supporting international students in higher education: a comparative examination of approaches in the UK and U.S.A. Learning and Teaching, 4(2), pp. 30 44.

Bennett, D. (2006) The effectiveness of current student ambassadors in higher education marketing, recruitment and retention. The Marketing of Higher Education, 3-7 January 2006, Intercollege, Nicosia, Cyrpus.

Bennett, D. (2009) Student mentoring prior to entry: getting accurate messages across In: A. Cook and B. S. Rushton (ed.) How to recruit and retain higher education students: a handbook of good practice. London: Routledge.

Bhugra, D., and Becker, M. A. (2005) Migration, cultural bereavement and cultural identity. World Psychiatry, 4(1), pp. 18-24.

Braun, V., \& Clarke, V. (2006). Using thematic analysis in psychology. Qualitative research in psychology, 3(2), pp. 77-101.

Chinese Students and Scholars Association at University of Pittsburgh (CSSA) (2009) Welcome to University of Pittsburgh. Retrieved from: http://www.pittcssa.net accessed on 31 August 2012.

Choudaha, R. and Chnag, L. (2012) Trends in International Student Mobility, Research Report for WES Research and Advisory Services. Retrieved from: http://www.wes.org/ras/TrendsInInternationalStudentMobility.pdf accessed on 31 August 2012, accessed 31 August 2012.

Davies, B. (1994) Durkheim and the sociology of education in Britain. British Journal of Sociology of Education 15, pp. 3-25.

De Vita, G. and Case, P. (2003) Rethinking the internationalization agenda in UK higher education. Journal of Further and Higher Education, 27(4), pp. 383-398.

Denman, B. and Hilal, K. (2011) From barriers to bridges: An investigation on Saudi student mobility (2006-2009), International Review of Education, 57, pp. 299-318.

EIF: European Integration Forum, (2011) Summary Report: Fifth meeting of the European Integration Forum 'Integration through local action', Brussels, 23-24 May 2011. Retrieved from: http://ec.europa.eu/ewsi/UDRW/images/items/static_38 992519171.pdf accessed on 06 September 2012.

Gallucci, S (2011) Language learning, identities and emotions during the year abroad: Case studies of British Erasmus students in Italy, $\mathrm{PhD}$ thesis University of Birmingham. Retrieved from: http://etheses.bham.ac.uk/1735/1/Gallucci 11 PhD.pdf accessed on 07 September 2012.

Harris, R. (1995) Overseas Students in the United Kingdom University System, Higher Education, 29, pp.77-92.

Heczková, L., and Jašková, M. (2010) Erasmus mobility: students' motivation and Satisfaction. Retrieved from: 
http://www.eracon.info/assets/files/2010/Full\%20Papers/LenkaHeczkova_Czech\%20Republic.pdf accessed on 07 September 2012.

HESA: The Higher Education Statistics Agency (2014) available online from https://www.hesa.ac.uk/free-statistics. Accessed on 26 Jan 2015

Ibrahim, A. (1999) Becoming Black: Rap and Hip-Hop, Race, Gender, Identity, and the Politics of ESL Learning. TESOL Quarterly, 33(3), pp. 349-369.

King, R and Ruiz-Gelices, E (2003) International Student Migration and the European 'Year Abroad': Effects on European Identity and Subsequent Migration Behaviour. International Journal of Population Geography, 9, pp. 229-252.

Kritz, M. (2015) Why Do Countries Differ in Their Rates of Outbound Student Mobility? Journal of Studies in International Education, 32 (5), pp. 567-594.

Lash, S. (2002) Foreword by Scott Lash: individualization in a non-linear mode. In Beck U, BeckGernsheim E. (ed.) Individualization, London: Sage.

Maclean, R (2010) First-year Law Students construction of professional identity through writing. Discourse Studies, 12(2), pp. 177-194.

Mwale, S. (2014) Secrecy and Knowledge Production: doing research in corporate organisational settings, Review of Social Studies, Vol 1No. 1(133-152) http://rossjournal.co.uk/ross-review-ofsocial-studies-paper-first-issue-methodological-choices-and-challenges/

Phillipson, R.H.L. (1992) Linguistic Imperialism. Oxford: Oxford University Press.

Saudi Students Club in London [SSCL] (2012) Retrieved from: http://www.ssclondon.com/portal/ accessed on 6th September 2012

Schweisfurth, M., and Gu, Q. (2009) Exploring the experiences of international students in UK higher education: possibilities and limits of interculturality in university life. Intercultural Education, 20(5), pp. 463-473.

Singh. J, Schapper. J, and Jack, G. (2014) The Importance of Place for International Students' Choice of University: A Case Study at a Malaysian University. Journal of Studies in International Education, 18(5), pp. 463-474.

Skeldon, R. (1997) Migration and Development: A Global Perspective. London: Longman.

Stier, J. (2002) Internationalisation in higher education: Unexplored possibilities and unavoidable challenges. Paper presented at the European conference on educational research, September 11_14, in University of Lisbon.

The Organisation for Economic Co-operation and Development (2011) Education at a Glance. Paris: OECD. 
Toohey, K. and Norton, B. (2010) Language learner identities and sociocultural worlds. In R. B. Kaplan (ed.), The Oxford handbook of applied linguistics (2nd ed.). New York: Oxford University Press, pp. 178-188.

Turner, Y., and Robson, S. (2008) Internationalising the university. London: Continuum.

University of Sussex Islamic Society [USISOC] (2012) About Us. Retrieved from: http://www.usisoc.org.uk/about-us accessed on 6th September 2012.

Verbik, L and Lasanowski, V. (2007) International student Mobility: Patterns and Trends, The Observatory on Borderless Higher Education. Retrieved from: http://www.eua.be/fileadmin/user_upload/files/newsletter/International_Student_Mobility__Patterns_and_Trends.pdf accessed on 6th September 2012. 